Published in final edited form as:

J Am Chem Soc. 2006 July 19; 128(28): 9248-9256.

\title{
Evaluation of Biologically Relevant Short $\alpha$-Helices Stabilized by a Main-Chain Hydrogen-Bond Surrogate
}

\author{
Deyun Wang, Kang Chen, John L. Kulp III, and Paramjit S. Arora \\ Contribution from the Department of Chemistry, New York University, New York, New York 10003
}

\section{Abstract}

We previously reported the design and synthesis of a new class of artificial $\alpha$-helices in which an Nterminal main-chain hydrogen bond is replaced by a carbon-carbon bond derived from a ring-closing metathesis reaction [Chapman, R. N.; Dimartino, G.; Arora, P. S. J. Am. Chem. Soc.2004, 126, 12252-12253]. Our initial study utilized an alanine-rich sequence; in the present manuscript we evaluate the potential of this method for the synthesis of very short (10 residues) $\alpha$-helices representing two different biologically relevant $\alpha$-helical domains. We extensively characterized these two sets of artificial helices by NMR and circular dichroism spectroscopies and find that the hydrogen-bond surrogate approach can afford well-defined short $\alpha$-helical structures from sequences that do not spontaneously form $\alpha$-helical conformations.

\section{Introduction}

$\alpha$-Helical domains are frequently found at protein interfaces and play a major role in mediating protein-protein interactions. ${ }^{1}$ Stable mimics of these domains would have wide-ranging applications as reagents for molecular biology and as leads in drug discovery. Stabilization of short peptides in $\alpha$-helical conformation remains a challenging endeavor especially if the sequence is not altered or is not predisposed to forming a helical structure. ${ }^{2}$ The helix-coil transition theory in peptides suggests that the energetically demanding organization of three consecutive amino acids into the helical orientation inherently limits the stability of short $\alpha$ helices. ${ }^{3,4}$ According to this theory, $\alpha$-helices composed of 10 or less amino acids are expected to be essentially unstable due to a low nucleation probability. ${ }^{5,6}$ Methods that afford preorganized $\alpha$-turns might be expected to overcome the intrinsic nucleation barrier and initiate helix formation. ${ }^{7-10}$ In an $\alpha$-helix, a hydrogen bond between the $\mathrm{C}=\mathrm{O}$ of the $i$ th amino acid residue and the $\mathrm{NH}$ of the $i+4$ th amino acid residue stabilizes and nucleates the helical structure (Figure 1). To mimic the $\mathrm{C}=\mathrm{O}--\mathrm{H}-\mathrm{N}$ hydrogen bond as closely as possible and to preorganize the $\alpha$-turn, we envisioned a covalent bond of the type $\mathrm{C}=\mathrm{X}-\mathrm{Y}-\mathrm{N}$, where $\mathrm{X}$ and $\mathrm{Y}$ would be part of the $i$ and the $i+4$ residues, respectively. In our method, the covalent bond between the $i$ and the $i+4$ residues is a carbon-carbon bond derived from a ring-closing metathesis reaction. 11,12 This approach was inspired by the work of Satterthwait and co-workers who utilized a hydrazone-link to connect the residues; although, it is unclear if exchange of the hydrogen bond with the hydrazone provided well-defined $\alpha$-helices. ${ }^{13}$ We have demonstrated that stable artificial $\alpha$-helices can be developed by replacing a main-chain hydrogen bond with a carboncarbon bond.

E-mail: arora@nyu.edu.

Supporting Information Available: Synthesis, ${ }^{1} \mathrm{H}$ NMR, ${ }^{13} \mathrm{C}$ NMR, and HRMS of modified amino acids. Synthesis and characterization (HPLC and MS) of peptides. Circular dichroism and 2D NMR spectra, and distance restraints used for the calculation of the NMR structure of $\mathbf{3}$ (PDF). This material is available free of charge via the Internet at http://pubs.acs.org. 
A key feature of this hydrogen-bond surrogate (HBS) approach is that the internal placement of the cross-link affords short helices with minimal perturbations to their molecular recognition surfaces. This method differs significantly from the commonly employed side-chain crosslinking methods for helix stabilization. ${ }^{2,14,15}$ A limitation of the latter approach is that side chain functionality must be sacrificed to nucleate stable helical conformations. The modified side chains are unavailable for molecular recognition, and the resulting tether blocks at least one face of the putative helix. The HBS approach uniquely allows synthesis of artificial helices with all side chains available for molecular recognition and does not place any steric encumbrances on the helix surface. We recently showed that HBS $\alpha$-helices can bind their expected protein receptor with high affinity, whereas the side-chain cross-linked helices composed of the same sequence failed to target this receptor. ${ }^{16}$

This manuscript presents a detailed evaluation of the hydrogen-bond surrogate approach for stabilizing two 10-mer peptide sequences into the $\alpha$-helical conformations. The test peptides $\mathbf{1}$ and $\mathbf{2}$ are derived from the Bak BH3 and the c-Jun coiled-coil domains, respectively (Figure 2). ${ }^{17,18}$ These peptides were chosen because they represent two different alpha-helices involved in protein-protein interactions allowing us to gauge the potential of our method for the preparation of biologically important compounds from very short peptide sequences. We also selected these sequences because helix-coil prediction algorithms (AGADIR19 and Helixcoil ${ }^{20}$ ) suggested that these short sequences should be essentially disordered allowing us to determine the suitability of the HBS approach for stabilization of nonhelix forming ("difficult") sequences. We synthesized HBS $\alpha$-helices $\mathbf{3}$ and $\mathbf{4}$ that correspond to peptides $\mathbf{1}$ and 2; these artificial helices contain 13-membered macrocycles that closely mimic the 13membered hydrogen-bonded ring in an $\alpha$-turn (Figure 2). Extensive NMR and circular dichroism spectroscopies were used to examine the structure and stability of these HBS $\alpha$ helices. We demonstrate that the HBS approach affords stable short $\alpha$-helices from biologically relevant (non-alanine- rich) sequences

\section{Results}

\section{Synthesis}

Solid-phase synthesis of peptides was achieved using standard Fmoc protocols on Rink amide resin (Scheme 1). The metathesized peptides (3-4) were generated from the corresponding bisolefin peptides (5-6) following treatment of the resin with the RCM catalyst as described. ${ }^{12}$ Peptides were cleaved from the resin with trifluoroacetic acid and purified by HPLC. All peptides were characterized by mass spectrometry; HBS helices $\mathbf{3}$ and $\mathbf{4}$ were further characterized by NMR. The metathesis reaction on the peptide bis-olefins typically affords a very high ratio of the trans to cis alkene; we were unable to isolate the cis isomers for the current study. ${ }^{21}$ The alkene geometry of the isolated metathesis products was determined by NMR spectroscopy by homonuclear decoupling experiments. We assigned the alkene geometry in both 3 and $\mathbf{4}$ as trans based on the coupling constants $(15 \mathrm{~Hz})$. The decoupled spectra are shown in the Supporting Information, Figures S9 and S12, for HBS $\alpha$-helices 3 and 4, respectively.

\section{Characterization by Circular Dichroism}

The helicity of the constrained and control peptides was investigated by circular dichroism spectroscopy. CD studies were performed in different percentages of trifluoroethanol (TFE) and acetonitrile (ACN) solutions in phosphate buffered saline (PBS) to obtain a measure of their helical content. Figure 3 shows the CD spectra of HBS $\alpha$-helices $\mathbf{3}$ and $\mathbf{4}$ along with their unconstrained peptide counterparts 1 and 2, respectively, in 10\% TFE in PBS. As expected, unconstrained peptides $\mathbf{1}$ and $\mathbf{2}$ display spectra typical of unstructured or slightly helical peptides. Peptide $\mathbf{2}$ appears to be significantly less $\alpha$-helical than $\mathbf{1}$; while peptide $\mathbf{1}$ is slightly $\alpha$-helical, the CD spectrum of $\mathbf{2}$ strongly resembles those of largely disordered peptides or 
polyproline-II helices. ${ }^{22}$ From these CD studies, we concluded that it would be significant to generate a highly stable helix from $\mathbf{1}$, but it would be quite remarkable if the HBS method could provide stable helices from 2 .

We were gratified to observe that HBS $\alpha$-helices $\mathbf{3}$ and $\mathbf{4}$ display double minima at 208 and $222 \mathrm{~nm}$ and maxima near $190 \mathrm{~nm}$ consistent with those observed for canonical $\alpha$-helices. The relative percent helicity of peptides can be estimated by the mean residue ellipticity at $222 \mathrm{~nm}$, although these estimates are typically not accurate for short helices. ${ }^{2,8} \mathrm{We}$ used the equation described by Baldwin ${ }^{23}$ and recently modified by Fairlie ${ }^{2}$ to calculate percent helicity for short peptides from the ratio $[\theta]_{222} /[\theta]_{\max }$, where $\left.[\theta]_{\max }=(-44000+250 T)(1-k / n)\right]$. The $[\theta]_{\max }$ for 10-residue $\alpha$-helices is calculated to be -23400 for $k=4.0$ and $T=20^{\circ} \mathrm{C}$. As discussed by Fairlie and Baldwin, the correct value of $k$ (finite length correction) remains difficult to define for short peptides. We used the same value for $k$ as found suitable by Fairlie; the value of $\theta_{\max }$ obtained with this $k$ agrees well with the $\theta_{\max }(-22000)$ obtained for a 12 mer lactambridged $\alpha$-helix by Kallenbach and co-workers through TFE titration studies. ${ }^{24}$ With this $\theta_{\max }$, the $\%$ helicity of $\mathbf{3}$ varies from 46 to $85 \%$ and that of $\mathbf{4}$ ranges from 32 to $62 \%$ depending on the percentage (0-20\%) of organic cosolvent in PBS (Table 1). Addition of organic cosolvents is known to increase the amount of helical conformation. ${ }^{25,26}$ Both HBS-helices reach their respective maximum helicity in approximately $20 \%$ TFE (data not shown), whereas the unconstrained peptides $\mathbf{1}$ and $\mathbf{2}$ remain relatively unstructured in this solvent (Table 1 and Supporting Information, Figure S26).

The ratio of the 222 and $208 \mathrm{~nm}$ bands is occasionally used as an additional gauge of $\alpha$-helicity; however, the origin and effect of peptide sequence on this ratio remains ill-defined. ${ }^{24}$ Nevertheless, we were pleased to observe that the ratio of 222 and $208 \mathrm{~nm}$ bands in the HBS $\alpha$-helices 3 and 4 fall in the range (1.25-1.75) expected for canonical $\alpha$-helices. ${ }^{27}$ This ratio ranges from 0.08 to 0.65 in the CD spectra of unconstrained peptides 1 and 2 (Table 1). In summary, the CD studies are consistent with the hypothesis that the HBS method can effectively stabilize the $\alpha$-helix structure in two short nonalanine- rich sequences.

\section{Thermal Stability of HBS Helices}

The thermal stabilities of $\mathbf{3}$ and $\mathbf{4}$ were investigated by monitoring the temperature-dependent change in the intensity of the $222 \mathrm{~nm}$ bands in the CD spectra (Figure 3c). We observe a gradual increase in the signal intensity at $222 \mathrm{~nm}$ with temperature, which indicates helix unwinding at high temperatures. Nevertheless, we find that HBS helices $\mathbf{3}$ and $\mathbf{4}$ show a remarkable degree of thermal stability as the two peptides retain $60-70 \%$ of their room-temperature helicity at 85 ${ }^{\circ} \mathrm{C}$.

\section{Characterization by NMR}

Circular dichroism spectroscopy provides compelling evidence that the hydrogen bond surrogate approach can stabilize $\alpha$-helical structure in two different biologically relevant sequences. However, CD spectroscopy does not allow a detailed analysis of the peptide structure at the atomic level. For instance, we wanted to determine if the helical structure propagates uninterrupted to the $\mathrm{C}$-terminus and if all amino acid residues occupy the $\alpha$-helical conformation as dictated by the Ramachandran plot. For answers to these pertinent questions, we fully characterized compounds 3 and $\mathbf{4}$ by NMR spectroscopy. The NMR studies were performed in $20 \% \mathrm{CF}_{3} \mathrm{CD}_{2} \mathrm{OD}$ in PBS rather than in lower amounts of $d_{3}$-TFE; we used this solvent mixture for two reasons: (1) in purely aqueous solutions or $10 \%$ TFE solutions, both helices showed observable aggregation at concentrations needed for NMR studies, and (2) this solvent system provided minimal peak overlap allowing unambiguous assignment of a larger percentage of resonances. 
NMR spectroscopy allows several different means for gauging $\alpha$-helical structure in peptides including evaluation of key medium and long-range NOEs, coupling constants and $\varphi$ angle values, temperature-dependence of amide $\mathrm{NH}$ chemical shifts, and rates of amide proton exchange. ${ }^{28}$ We used all of these experiments to probe the structure of compounds 3 and 4 . These NMR studies provide unambiguous evidence that the hydrogen-bond surrogate approach leads to highly stable short $\alpha$-helices.

\section{D NMR Spectroscopy}

A combination of 2D TOCSY, DQF-COSY, and NOESY spectroscopy was used to assign ${ }^{1} \mathrm{H}$ NMR resonances for the HBS helices. ${ }^{29}$ Sequential NN $(i$ and $i+1)$ NOESY crosspeaks, a signature of helical structure, were observed for both sequences as shown in the NOE correlation charts (Figure 4), although spectral overlap prevented assignment of some key cross-peaks. The NOESY spectrum further reveals several nonsequential medium range NOEs, for example, $d \alpha \mathrm{N}-(i, i+3), d \alpha \mathrm{N}(i, i+4)$, and $d \alpha \beta(i, i+3)$, that provide unequivocal evidence for the helical structure. The fact that we can detect NOEs involving the last residues in both peptides indicates that the helices have not started fraying at the C-termini.

\section{Amide Proton Temperature Coefficients}

The amide proton chemical shift is temperature sensitive, and the magnitude of this shift is indicative of the extent to which the particular amide proton is hydrogen-bonded. ${ }^{30}$ If an amide proton exchanges slowly with a temperature coefficient more positive than $-4.5 \mathrm{ppb} / \mathrm{K}$, it is considered to be hydrogen-bonded. Figure $5 \mathrm{a}$ and $5 \mathrm{c}$ show the temperature-dependent chemical shifts for main-chain amide protons in helices $\mathbf{3}$ and $\mathbf{4}$, respectively. The temperature coefficients for $\mathbf{3}$ are listed in Table 2, and those for $\mathbf{4}$, in Table 3. We find that most amide temperature coefficients in helices $\mathbf{3}$ and $\mathbf{4}$ fall in the range considered indicative of hydrogenbonded amides. The major exceptions are valine- 2 in $\mathbf{3}$ and isoleucine- 2 in $\mathbf{4}$ with coefficients between 8 and $10 \mathrm{ppb} / \mathrm{K}$ indicating that these amide protons are not forming intramolecular hydrogen bonds. This is expected as these residues reside at the $\mathrm{N}$-terminus of the helices and do not have intramolecular hydrogen-bonding partners.

\section{Amide Proton Exchange Rates}

Backbone amide hydrogen-deuterium exchange offers a sensitive tool for examining protein structure and dynamics. ${ }^{31,32}$ The amide exchange rates for unstructured peptides in aqueous solutions are often too fast to measure; however if the amide hydrogen is protected from exchange, i.e., through hydrogen-bonding, the exchange rates can slow by several orders of magnitude. Relative rate constants for the H/D exchange, along with the temperature coefficients, provide important insights regarding the involvement of individual amino acid residues in intramolecular hydrogen bonds. Figure $5 b$ and $5 d$ show H/D exchange curves for helix $\mathbf{3}$ and $\mathbf{4}$, respectively. The tabulated exchange rates for $\mathbf{3}$ are shown in Table 2, and those for 4, in Table 3. The data in Figure 5 show that the individual hydrogen-exchange rates in these helices can be determined precisely. ${ }^{33}$ The measured exchange rates, $k_{\mathrm{ex}}$, can be compared to the predicted intrinsic chemical exchange rate, $k_{\mathrm{ch}}$, for an unstructured peptide of the same sequence, to assess individual protection factors $\left(\log k_{\mathrm{ch}} / k_{\mathrm{ex}}\right)$ and the corresponding free energies of protection $(\Delta G)$. The predicted intrinsic chemical exchange rates, protection factors, and the free energy of protection were calculated using the spreadsheet at http://hx2.med.upenn.edu/download.html and are shown in Tables 2 and 3 for peptides $\mathbf{3}$ and 4, respectively. The data indicate that HBS $\alpha$-helix $\mathbf{3}$ contains a highly stable hydrogen-bonded network with significant protection factors and associated free energies of protection (1.5-3.9 $\mathrm{kcal} / \mathrm{mol}$ ). Such a degree of stabilization is typically observed for buried amide protons in proteins but not in short peptides. ${ }^{14,34}$ The exchange rates observed for helix $\mathbf{3}$ are slower than those observed for $\mathbf{4}$, and this result is consistent with the circular dichroism studies which 
showed that $\mathbf{4}$ is less helical than $\mathbf{3}$. As expected, we observed rapid exchange rates for unconstrained peptide analogues $\mathbf{1}$ and $\mathbf{2}\left(k \approx 10^{-3} \mathrm{~S}^{-1}\right.$, data not shown).

\section{${ }^{3} J_{\mathrm{NHCH} \alpha}$ Coupling Constants}

The ${ }^{3} J_{\mathrm{NHCH} \alpha}$ coupling constant provides a measure of the $\varphi$ angle and affords intimate details about the local conformation in peptides and proteins. ${ }^{28} \mathrm{The}^{3} J_{\mathrm{NHCH} \alpha}$ values typically range between 4 and $6 \mathrm{~Hz}(-70<\varphi<-30)$ for $\alpha$-helices, and a series of three or more coupling constants in this range are indicative of the $\alpha$-helical structure. The calculated $\varphi$ angles, derived from coupling constants, for HBS $\alpha$-helix $\mathbf{3}$ are listed in Table 2, and those for $\mathbf{4}$, in Table 3. All coupling constants and the $\varphi$ angles for $\mathbf{3}$ fall in the range expected for $\alpha$-helical peptides with the exception of coupling constants for residues at the termini (Q1 and Y10). In 4, all residues with the exception of $\mathrm{E} 7$ and $\mathrm{K} 8$ display $\varphi$ angle values characteristic of a stable $\alpha$ helical structure.

In summary, the NMR studies provide key NOEs characteristic of well-defined $\alpha$-helical structures; the coupling constant values unambiguously indicate that the residues adopt conformations expected of $\alpha$-helical peptides and that the low temperature dependence and the slow H/D exchange rates displayed by amide protons are consistent with their involvement in intramolecular hydrogen bonding.

\section{Solution Structure of 3}

The solution structure of the HBS $\alpha$-helix $-\mathbf{3}$ was determined from NOESY cross-peaks and ${ }^{3} J_{\mathrm{NHCH} \alpha}$ coupling constants using simulated annealing and energy minimization protocol in the Discover3 module of InsightII (Accelyrs, San Diego, CA). A total of 116 NOE restraints (36 medium and long range, 29 sequential, and 51 intraresidue) and $9 \varphi$ angle restraints were used during the dynamics. No explicit hydrogen bond restraints were used in the calculations. The final 20 lowest energy structures had one significant dihedral (Q1) and no significant distance violations (Figure 6). The violation for the Q1 dihedral angle was expected based on the ${ }^{3} J_{\mathrm{NHCH} \alpha}$ coupling constant (Table 2 ). The 20 conformer ensemble obtained for the peptide shows a backbone root-mean-squared deviation (RMSD) of $0.58 \pm 0.10 \AA$ and all heavy atom RMSD of $1.15 \pm 0.30 \AA$. The final structures clearly show a hydrogen bonding network along the backbone in an $i$ and $i+4$ configuration consistent with a well-defined $\alpha$-helix (Figure $6 \mathrm{c}$ ). From the top down view, it can be seen that the macrocycle does not protrude from the helix (Figure 6b). The entire ensemble of conformers did show a large spatial variation in the macrocycle region, mainly due to a limited set of medium and long range restraints defining this region. Because of overlapping peaks we could not fully delineate NOESY cros-speaks involving the hydrocarbon cross-link in the macrocycle and thus consider this region in the NMR-derived structure to be a semiqualitative model. The $\mathrm{C}$-terminal $\mathrm{NH}_{2}$ group is hydrogenbonded to the carbonyl of A7 in some of the low energy structures but not in all (Figure 6a). We observed a medium-sized NN ( $i$ and $i+1)$ NOE cross-peak between the C-terminal $\mathrm{NH}_{2}$ and the $\mathrm{NH}$ of $\mathrm{Y} 10$, but the simulation does not favor the hydrogen-bonded conformation over the other; the two conformations result from a single bond rotation. A Ramachandran map, generated from the MolMol molecular graphics program, representing the lowest 20 structures vividly displays the $\varphi$ and $\psi$ angles as being $\alpha$-helical (Figure 7). Overall, the NMR structure of 3 confirms our helix design principles that replacement of an $\mathrm{N}$-terminal hydrogen bond with a carbon-carbon bond allows synthesis of well-defined short $\alpha$-helices.

\section{Conclusions}

We are developing a new strategy for stabilizing short peptides in $\alpha$-helical conformation by replacing an $\mathrm{N}$-terminal hydrogen bond in the peptide sequence with a covalent bond derived from a ring-closing metathesis reaction. The resulting 13-membered macrocycle locks three 
amino acid residues in the $\alpha$-turn conformation overcoming the energetically demanding nucleation barrier for helix formation. The most significant feature of this method is that the entire solvent-exposed surface of the helical structure is available for molecular recognition. This paper describes extensive evaluation of this approach for the synthesis of biologically relevant short $\alpha$-helices. NMR and CD studies provide explicit evidence for well-defined structures. As the $\alpha$-helical domain is a critical component of protein interfaces, we expect short, stable HBS $\alpha$-helices to have significant potential as tools in a wide range of biological studies.

\section{Experimental Section}

\section{General}

Commercial-grade reagents and solvents were used without further purification except as indicated. All Fmoc amino acids, peptide synthesis reagents, and Rink Amide MBHA resin were obtained from Novabiochem (San Diego, USA). All other reagents were obtained from Sigma-Aldrich (St. Louis, USA). Reversed-phase HPLC experiments were conducted with 4.6 $\mathrm{mm} \times 150 \mathrm{~mm}$ (analytical scale) or $21.4 \mathrm{~mm} \times 150 \mathrm{~mm}$ (preparative scale) Waters $\mathrm{C}_{18}$ Sunfire columns using a Beckman Coulter HPLC equipped with a System Gold 168 Diode array detector. The typical flow rates for analytical and preparative HPLC were $1 \mathrm{~mL} / \mathrm{min}$ and $8 \mathrm{~mL} /$ $\mathrm{min}$, respectively. In all cases, $0.1 \%$ aqueous trifluoroacetic acid and acetonitrile buffers were used. Proton and carbon NMR spectra of monomers were obtained on a Bruker AVANCE 400 $\mathrm{MHz}$ spectrometer. Proton NMR spectra of HBS peptides were recorded on a Bruker AVANCE $500 \mathrm{MHz}$ spectrometer. High-resolution mass spectra (HRMS) were obtained on a LC/MSD TOF (Agilent Technologies). LCMS data were obtained on an Agilent 1100 series LC/MSD (XCT) electrospray trap.

\section{Synthesis of HBS a-Helices 3-4. General Procedure}

Resin bound bis-olefin peptides were synthesized by conventional Fmoc solid-phase chemistry on Rink amide resin with appropriate substitutions of $\mathrm{N}$-allylated dipeptide and 4-pentenoic acid or 5-hexenoic acid. In each coupling step, the appropriate Fmoc amino acid (4 equiv) was activated with HBTU (3.6 equiv) in 5\% DIPEA/NMP solution for 15 min and added to the resin-bound free amine. The resulting mixture was shaken for $60 \mathrm{~min}$. The coupling efficiency was monitored by ninhydrin test. After each coupling step, the Fmoc group was removed by treatment with $20 \%$ piperidine in NMP $(2 \times 20 \mathrm{~min})$. The bis-olefin containing resin was thoroughly washed with DMF, methanol, and dichloromethane, respectively, and dried under vacuum overnight before treatment with the metathesis catalyst. The ring-closing metathesis was performed on the dried bis-olefin resin bound peptide with the Hoveyda-Grubbs catalyst in a microwave synthesizer (Supporting Information). ${ }^{12}$ The resin was treated with the cleavage cocktail $\left(\mathrm{CF}_{3}-\mathrm{CO}_{2} \mathrm{H} / \mathrm{H}_{2} \mathrm{O} /\right.$ triisopropylsilane, 95:2.5:2.5) for $1.5 \mathrm{~h}$, and the resulting mixture was purified by reversed-phase HPLC to obtain the HBS helices in 40-60\% overall yield (calculated based on resin substitution).

\section{Spectroscopy}

CD spectra were recorded on an AVIV 202SF CD spectrometer equipped with a temperature controller using $1 \mathrm{~mm}$ length cells and a scan speed of $5 \mathrm{~nm} / \mathrm{min}$. The spectra were averaged over 10 scans with the baseline subtracted from analogous conditions as those for the samples. The samples were prepared in $10 \mathrm{mM}$ phosphate buffered saline, containing 0\%-20\% trifluoroethanol or $20 \%$ acetonitrile, with the final peptide concentration $50 \mu \mathrm{M}$. The concentrations of unfolded peptides were determined by the UV absorption of tyrosine residue at $275 \mathrm{~nm}$ in $6.0 \mathrm{M}$ guanidinium hydrochloride aqueous solution. The helix content of each peptide was determined from the mean residue $\mathrm{CD}$ at $222 \mathrm{~nm},[\theta]_{222}\left(\mathrm{deg} \mathrm{cm} \mathrm{dmol}^{-1}\right)$ corrected for the number of amino acids. Percent helicity was calculated from the ratio 
$[\theta]_{222} /[\theta]_{\max }$, where $[\theta]_{\max }=(-44000+250 T)(1-k / n)=-23400$ for $k=4.0$ and $n=10$ (number of amino acid residues in the peptide). 2,23 Please see the Results section for a discussion on the calculation of $\%$ helicity.

\section{Temperature-Dependent Amide Proton Chemical Shift Measurements}

All experiments were carried out on a Bruker AVANCE $500 \mathrm{MHz}$ spectrometer equipped with an inverse TXI probe and 3D gradient control. Samples of peptide $\mathbf{3}$ and $\mathbf{4}$ were prepared by dissolving $2 \mathrm{mg}$ of peptide in $450 \mu \mathrm{L}$ of PBS buffer, $30 \mu \mathrm{L}$ of $\mathrm{D}_{2} \mathrm{O}$, and $120 \mu \mathrm{L}$ of TFE- $d_{3}$ and adjusting the $\mathrm{pH}$ of the solution to 3.5 by adding $1 \mathrm{M} \mathrm{HCl}$. The 1D proton spectra or 2D TOCSY spectra (when overlapping is severe) were employed to read the chemical shifts of the amide protons. Solvent suppression was achieved with a 3919 Watergate pulse sequence.

Temperature ranges from $5{ }^{\circ} \mathrm{C}$ to $45^{\circ} \mathrm{C}$ at a $5{ }^{\circ} \mathrm{C}$ interval. At each temperature, the sample was allowed to equilibrate for $15 \mathrm{~min}$. Temperature was calibrated precisely by measurement of peak separation in $100 \%$ methanol $\left(<30{ }^{\circ} \mathrm{C}\right)$ or $80 \%$ ethylene glycol in DMSO $\left(>30{ }^{\circ} \mathrm{C}\right)$. The chemical shifts were calibrated with internal standard tetramethylsilane (TMS).

\section{D NMR Spectroscopy}

Spectra of peptide $\mathbf{3}$ (samples prepared as described above) were recorded on a Bruker Avance 500 at $20^{\circ} \mathrm{C}$, and those of 4 were recorded at $5{ }^{\circ} \mathrm{C}$. All $2 \mathrm{D}$ spectra were recorded by collecting 4092 complex data points in the $t_{2}$ domain by averaging 64 scans and 128 increments in the $t_{1}$ domain with the States-TPPI mode. All TOCSY experiments are performed with a mixing time of $80 \mathrm{~ms}$ on a $6000 \mathrm{~Hz}$ spin lock frequency, and all NOESY, with the mixing time of 200 $\mathrm{ms}$. The data were processed and analyzed using the Bruker TOPSPIN program. The original free induction decays (FIDs) were zero-filled to give a final matrix of 2048 by 2048 real data points. A $90^{\circ}$ sine-square window function was applied in both dimensions.

\section{Amide H-D Exchange Study}

Lyophilized samples of peptides 3 and $\mathbf{4}$ from the above experiments were dissolved in 600 $\mu \mathrm{L}$ of a $\mathrm{D}_{2} \mathrm{O} / \mathrm{TFE}-d_{3}$ mixture (80/20) to initialize the H-D exchange. The $\mathrm{pH}$ of the solution was confirmed. Spectra were recorded on a preshimmed Bruker AVANCE $500 \mathrm{MHz}$ spectrometer. The recorded temperature was $20^{\circ} \mathrm{C}$ both inside and outside the probe. The dead time was ca. $2 \mathrm{~min}$. The intensity changes for each amide proton were determined by monitoring either the $\mathrm{H}^{\mathrm{N}}$ peaks on 1D spectra or the cross-peaks between $\mathrm{H}^{\mathrm{N}}$ and $\mathrm{H}^{\alpha}$ on 2D TOCSY spectra when overlapping was severe. The peak height data were fit into one phase exponential equation to get the exchange rate constants using GraphPad Prism 4.0 program.

\section{Structure Calculations}

The solution structure of the peptide was computed using a typical simulated annealing molecular dynamics protocol followed by energy minimization in the Discover3 module (version 98.0) of InsightII (Accelyrs, San Diego, CA). The consistent valence force field $(\mathrm{CVFF}){ }^{36}$ was applied to three different starting conformations: $\beta$-sheet $\left(\varphi=-120^{\circ}, \psi=\right.$ $\left.+120^{\circ}\right)$, extended strand $\left(\varphi=-180^{\circ}, \psi=-180^{\circ}\right)$, and $\alpha$-helix $\left(\varphi=-60^{\circ}, \psi=-40^{\circ}\right)$. A total of 120 conformers were obtained (40 for each starting conformation) using 33 medium and long range, 36 sequential, and 42 intraresidue constraints. The 20 lowest energy structures from different starting conformations show minimal overall deviation (Supporting Information, Figure S25). These restraints were categorized into three groups: strong (2.5 $\AA$ upper limit), medium ( $3.5 \AA$ upper limit), and weak ( $5 \AA$ upper limit). These distances were employed using flat-bottom restraints with force constants of $10 \mathrm{kcal} / \mathrm{mol} / \AA^{2}$ and a maximum force value of $1000 \mathrm{kcal} / \mathrm{mol} / \AA^{2}$. Pseudoatom corrections were applied as necessary (Supporting Information, Table S2). The ${ }^{3} J_{\mathrm{NH}-\mathrm{CH} \alpha}$ coupling constants for all residues except $\mathrm{A} 3$ (due to lack of amide hydrogen) were used to calculate $\varphi$ angles by application of the Pardi 
parametrized Karplus equation. ${ }^{35,37}$ An implicit solvent was used for the simulated annealing and energy minimization using a distance-dependent dielectric (78.5) and no cutoffs for electrostatic interactions. Structures were analyzed with Pymol, ${ }^{38}$ MOLMOL, ${ }^{39}$ and InsightII. 40

\section{Supplementary Material}

Refer to Web version on PubMed Central for supplementary material.

\section{Acknowledgements}

We thank Professor Neville Kallenbach for valuable insights and helpful discussions. P.S.A is grateful for financial support from the NIH (GM073943), the donors of the American Chemical Society Petroleum Research Fund, Research Corporation (Cottrell Scholar Award), NYU (White-head Fellowship), and the New York State Office of Science, Technology and Academic Research (James D. Watson Investigator Award). We thank the NSF for equipment Grants MRI-0116222 and CHE-0234863 and the NCRR/NIH for Research Facilities Improvement Grant C06 RR-16572.

\section{References}

1. Walensky LD, Kung AL, Escher I, Malia TJ, Barbuto S, Wright RD, Wagner G, Verdine GL, Korsmeyer SJ. Science 2004;305:1466. [PubMed: 15353804]

2. Shepherd NE, Hoang HN, Abbenante G, Fairlie DP. J Am Chem Soc 2005;127:2974. [PubMed: 15740134]

3. Lifson S, Roig A. J Chem Phys 1961;34:1963.

4. Zimm BH, Bragg JK. J Chem Phys 1959;31:526.

5. Rohl CA, Chakrabartty A, Baldwin RL. Protein Sci 1996;5:2623. [PubMed: 8976571]

6. Yang JX, Zhao K, Gong YX, Vologodskii A, Kallenbach NR. J Am Chem Soc 1998;120:10646.

7. Austin RE, Maplestone RA, Sefler AM, Liu K, Hruzewicz WN, Liu CW, Cho HS, Wemmer DE, Bartlett PA. J Am Chem Soc 1997;119:6461.

8. Chin DH, Woody RW, Rohl CA, Baldwin RL. Proc Natl Acad Sci USA 2002;99:15416. [PubMed: 12427967]

9. Kemp DS, Curran TP, Davis WM, Boyd JG, Muendel C. J Org Chem 1991;56:6672.

10. Siedlecka M, Goch G, Ejchart A, Sticht H, Bierzyski A. Proc Natl Acad Sci USA 1999;96:903. [PubMed: 9927666]

11. Chapman RN, Dimartino G, Arora PS. J Am Chem Soc 2004;126:12252. [PubMed: 15453743]

12. Dimartino G, Wang D, Chapman RN, Arora PS. Org Lett 2005;7:2389. [PubMed: 15932205]

13. Cabezas E, Satterthwait AC. J Am Chem Soc 1999;121:3862.

14. Phelan JC, Skelton NJ, Braisted AC, McDowell RS. J Am Chem Soc 1997;119:455.

15. Schafmeister CE, Po J, Verdine GL. J Am Chem Soc 2000;122:5891.

16. Wang D, Liao W, Arora PS. Angew Chem, Int Ed 2005;44:6525.

17. O’Shea EK, Rutkowski R, Stafford WF III, Kim PS. Science 1989;245:646. [PubMed: 2503872]

18. Sattler M, Liang H, Nettesheim D, Meadows RP, Harlan JE, Eberstadt M, Yoon HS, Shuker SB, Chang BS, Minn AJ, Thompson CB, Fesik SW. Science 1997;275:983. [PubMed: 9020082]

19. Munoz V, Serrano L. J Mol Biol 1995;245:275. [PubMed: 7844817]

20. Chen, K.; Vologodskii, A.; Kallenbach, NR. Helixcoil Program. www.nyu.edu/projects/kallenbach

21. In unpublished studies, we find that the cis-alkene containing artificial helices are equally or slightly less helical than their trans-alkene counterparts.

22. Shi Z, Olson CA, Rose GD, Baldwin RL, Kallenbach NR. Proc Natl Acad Sci USA 2002;99:9190. [PubMed: 12091708]

23. Luo P, Baldwin RL. Biochemistry 1997;36:8413. [PubMed: 9204889]

24. Kallenbach, NR.; Lyu, PC.; Zhou, HX. CD spectroscopy and the helixcoil transition in peptides and polypeptides. In: Fasman, GD., editor. Circular Dichroism and the Conformational Analysis of Biomolecules. Plenum Press; New York: 1996. 
25. Rajan R, Balaram P. Int J Pept Protein Res 1996;48:328. [PubMed: 8919053]

26. CammersGoodwin A, Allen TJ, Oslick SL, McClure KF, Lee JH, Kemp DS. J Am Chem Soc 1996;118:3082.

27. Wallimann P, Kennedy RJ, Miller JS, Shalongo W, Kemp DS. J Am Chem Soc 2003;125:1203. [PubMed: 12553823]

28. Wuthrich, K. NMR of Proteins and Nucleic Acids. Wiley; New York: 1986.

29. Both peptide sequences contain arginine residues at the 4 th position. The amide protons of these residues display substantial upfield shifts in 3 and 4. Please see the Supporting Information for a discussion on the characteristics of the $\mathrm{R} 4$ residues.

30. Baxter NJ, Williamson MP. J Biomol NMR 1997;9:359. [PubMed: 9255942]

31. Bai Y, Milne JS, Mayne L, Englander SW. Proteins 1993;17:75. [PubMed: 8234246]

32. Connelly GP, Bai Y, Jeng MF, Englander SW. Proteins 1993;17:87. [PubMed: 8234247]

33. Englander SW, Kallenbach NR. Q Rev Biophys 1983;16:521. [PubMed: 6204354]

34. Zhou HXX, Hull LA, Kallenbach NR, Mayne L, Bai YW, Englander SW. J Am Chem Soc 1994;116:6482.

35. Karplus M. J Chem Phys 1959;30:11.

36. Dauber-Osguthorpe P, Roberts VA, Osguthorpe DJ, Wolff J, Genest M, Hagler AT. Proteins 1988;4:31. [PubMed: 3054871]

37. Pardi A, Billeter M, Wuthrich K. J Mol Biol 1984;180:741. [PubMed: 6084720]

38. DeLano, WL. The PyMOL Molecular Graphics System. DeLano Scientific; San Carlos, CA: 2003.

39. Koradi R, Billeter M, Wuthrich K. J Mol Graphics Modell 1996;14:51.

40. Insight II version 2000. Molecular Simulations Inc; San Diego, CA: 

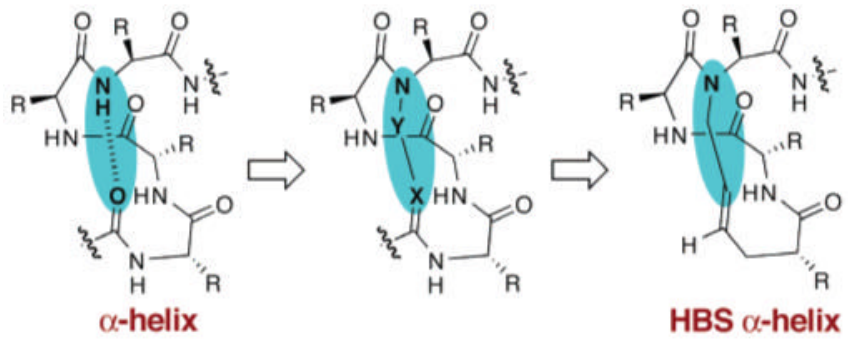

HBS $\alpha$-helix

Figure 1.

Nucleation of short $\alpha$-helices by replacement of an $\mathrm{N}$-terminal $i$ and $i+4$ hydrogen bond $(\mathrm{C}=\mathrm{O}-$ $\mathrm{H}-\mathrm{N})$ with a covalent link $(\mathrm{C}=\mathrm{X}-\mathrm{Y}-\mathrm{N})$. The hydrogen-bond surrogate-based (HBS) $\alpha$-helices contain a carbon-carbon bond derived from an olefin metathesis reaction. 
1: ACQVARQLAEIY-NH

2: AcRIARLEEKYK-NH

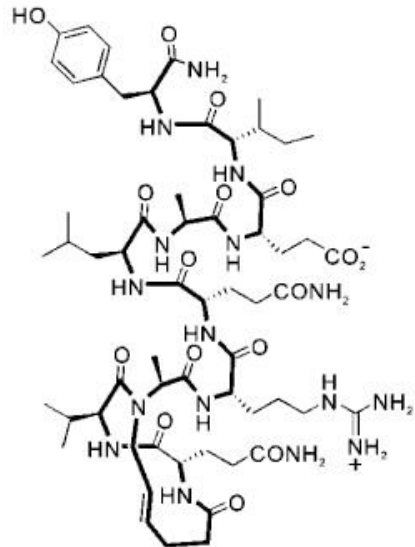

3
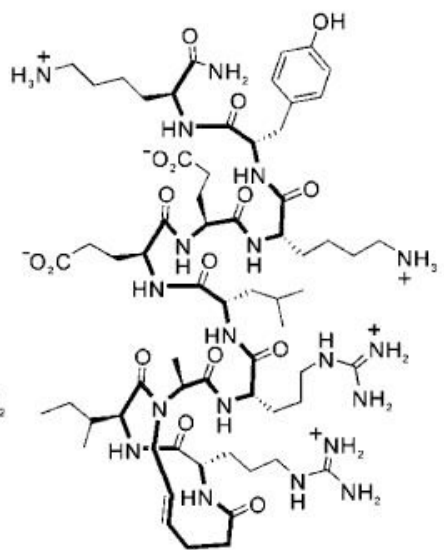

4

Figure 2.

Unconstrained peptides and HBS $\alpha$-helices used to evaluate the hydrogen-bond surrogate strategy. 

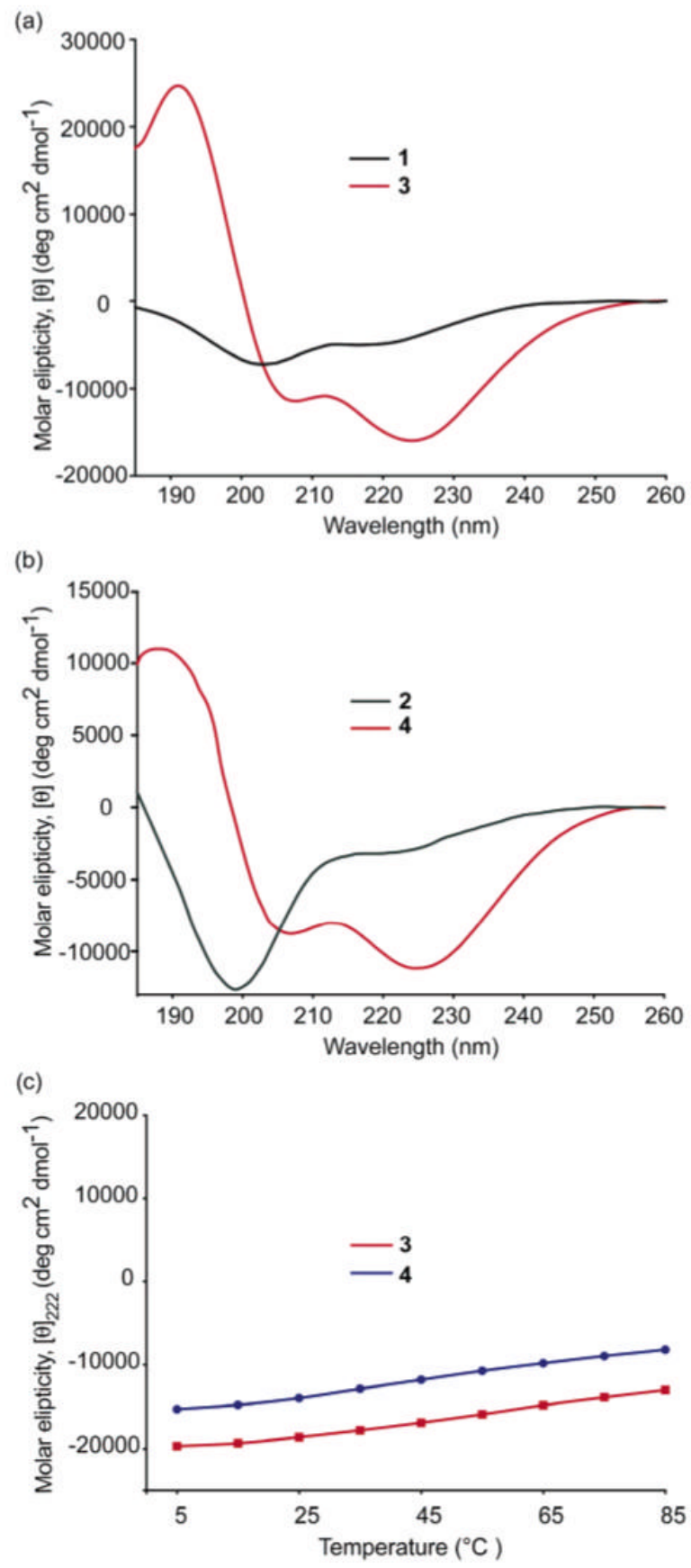

Figure 3.

( $\mathrm{a}$ and $\mathrm{b}$ ) Circular dichroism spectra of unconstrained peptides 1 and 2 and their HBS analogues 3 and 4, respectively. (c) Effect of temperature on the stability of HBS $\alpha$-helices 3 and 4 . The CD spectra were obtained in $10 \%$ TFE/PBS. 
(a)

(c)

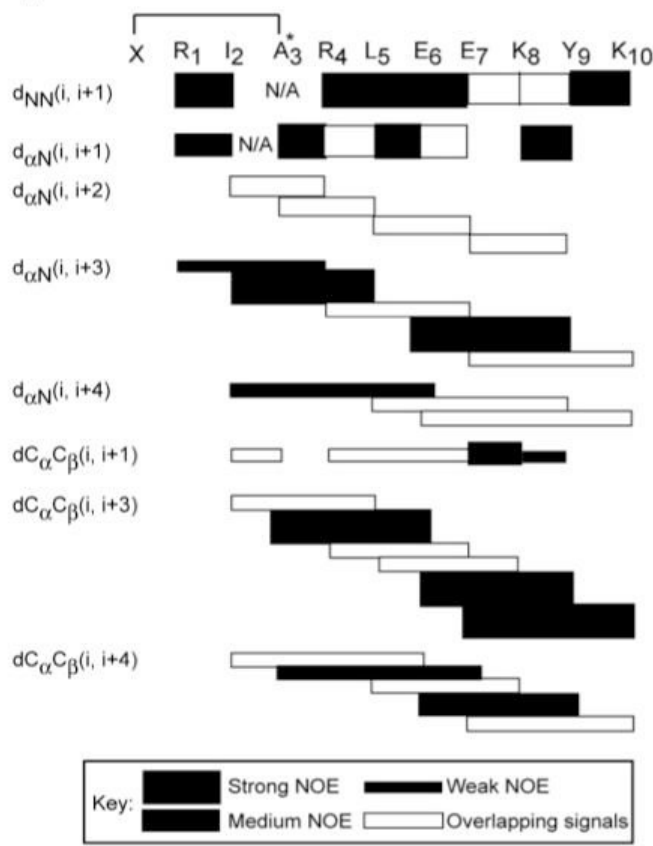

(b)

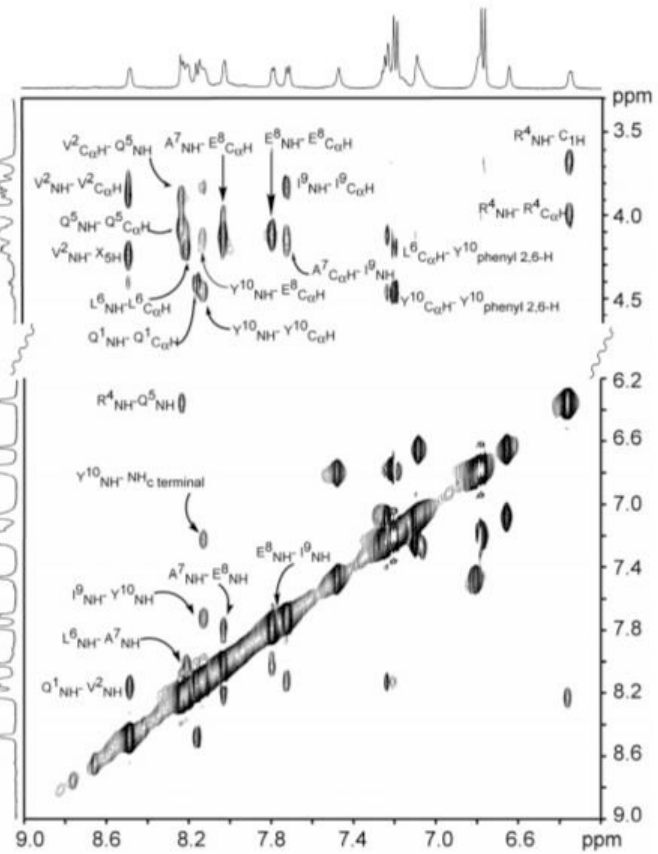

(d)
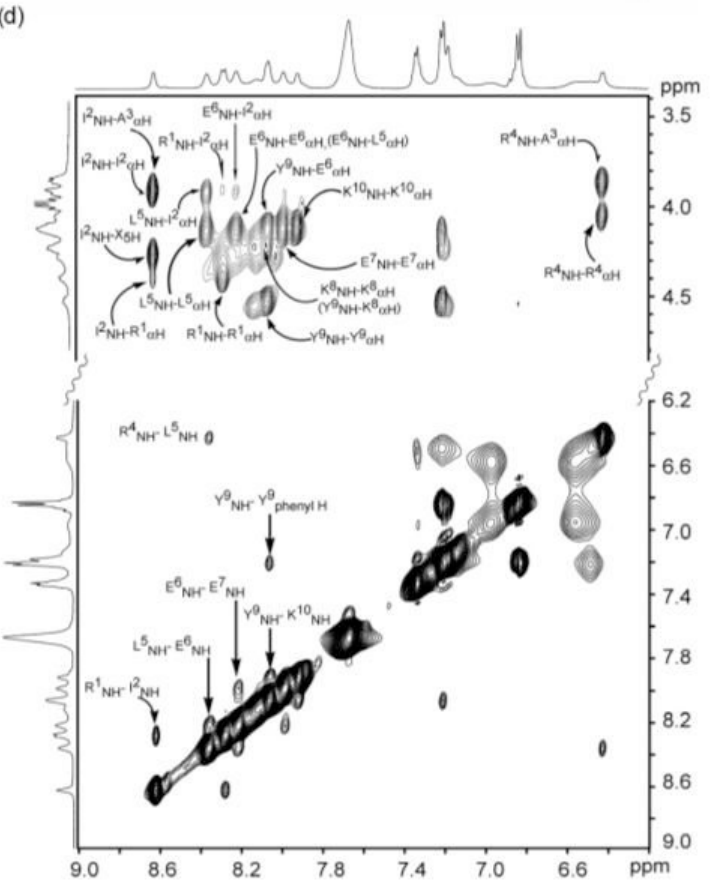

Figure 4.

NOESY correlation charts and cross-sections of NOESY spectra for 3 (a, b) and 4 (c, d). The alanine-3 residues in both artificial helices are $N$-alkylated. Filled rectangles indicate relative intensity of the NOE cross-peaks. Empty rectangles indicate NOE that could not be unambiguously assigned because of overlapping signals. 
(a)

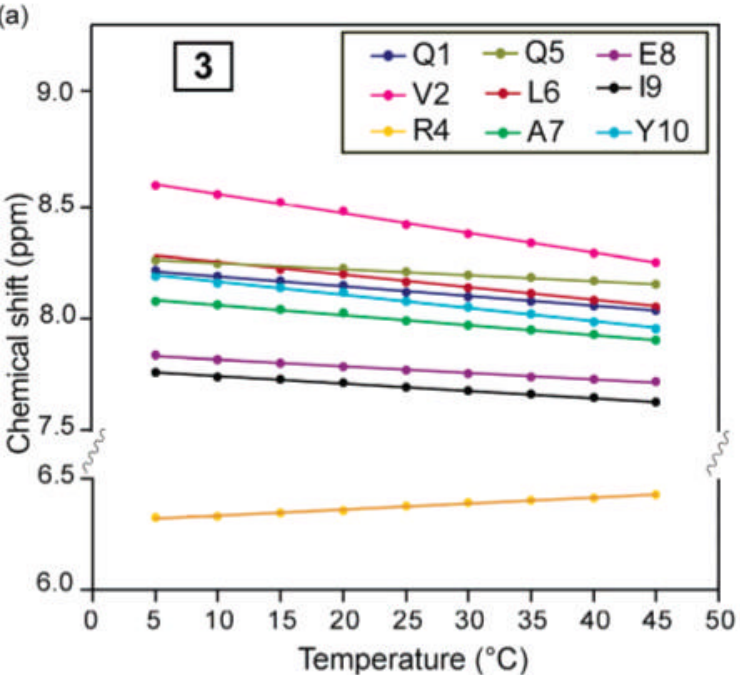

(b)

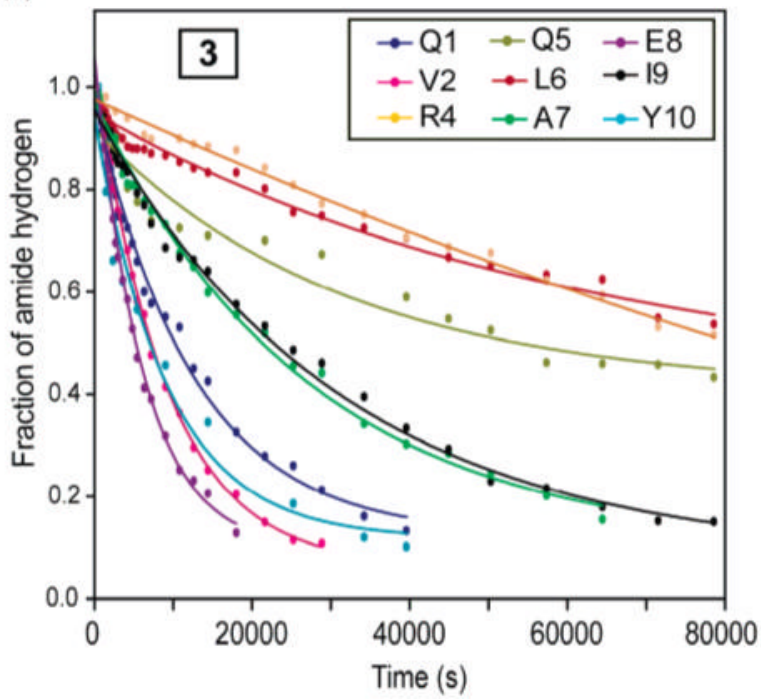

(c)

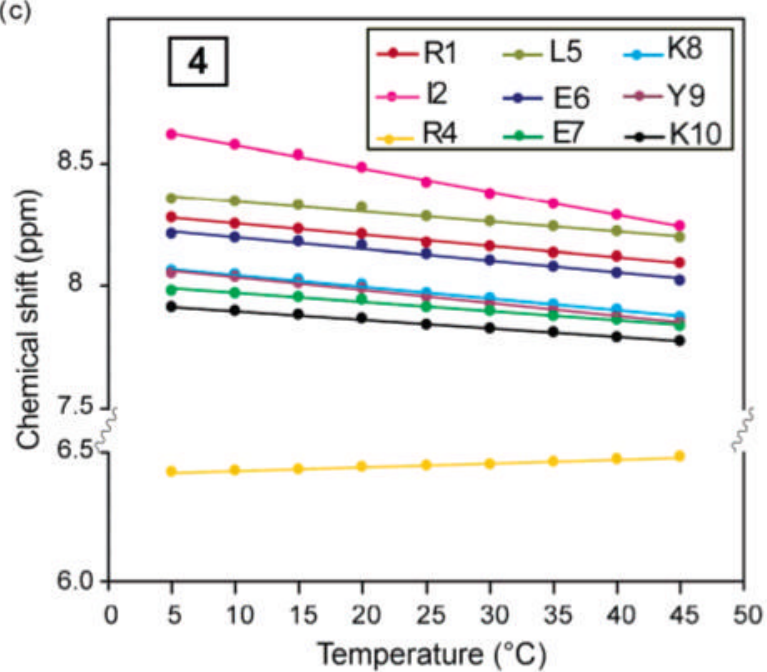

(d)

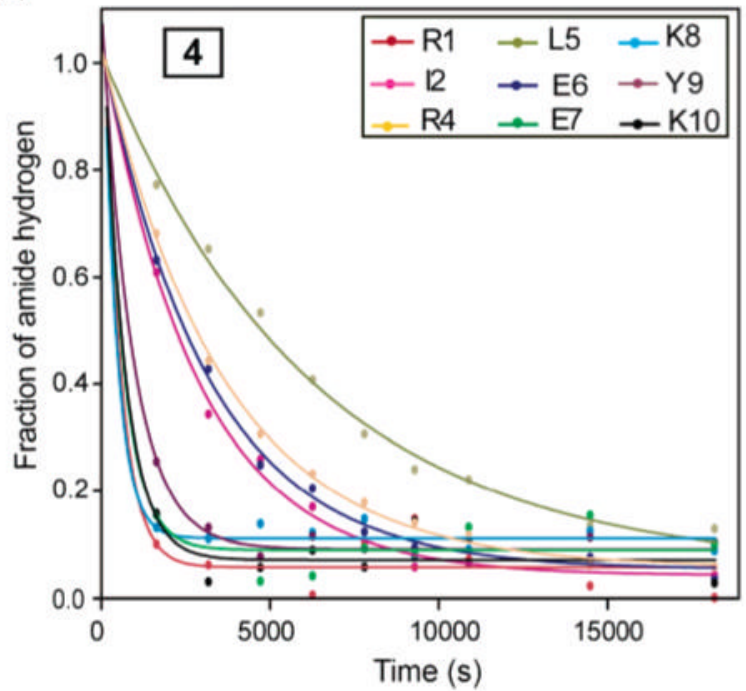

Figure 5.

Temperature-dependent chemical shifts $(\mathrm{a}, \mathrm{c})$ and hydrogen-deuterium exchange plots (b, d) for backbone amide protons in $\mathbf{3}$ and $\mathbf{4} .^{29}$ 
(a)

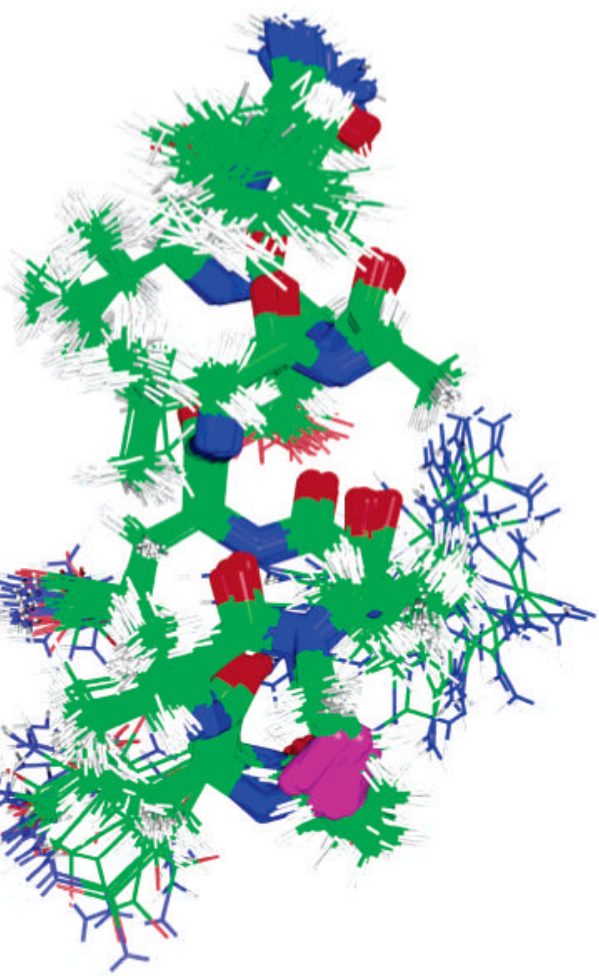

(b)

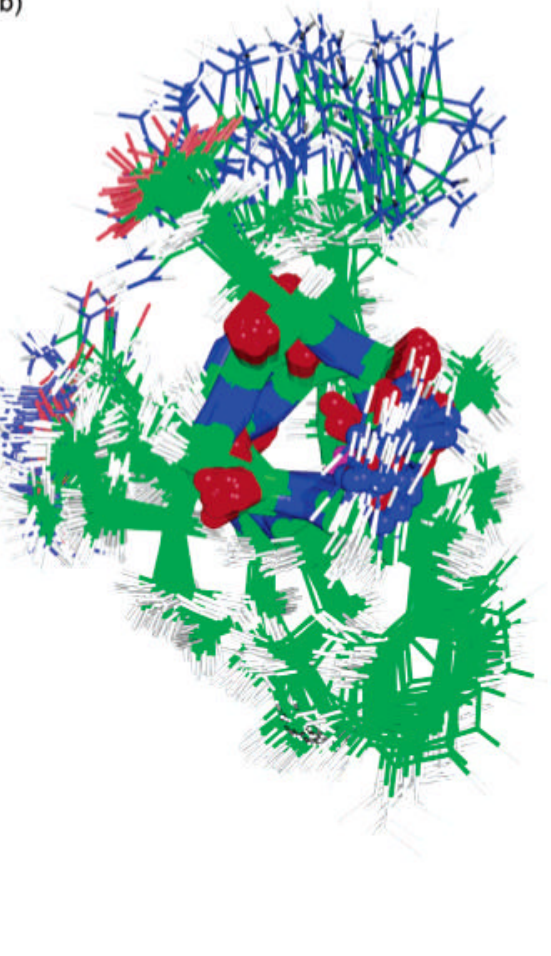

(c)

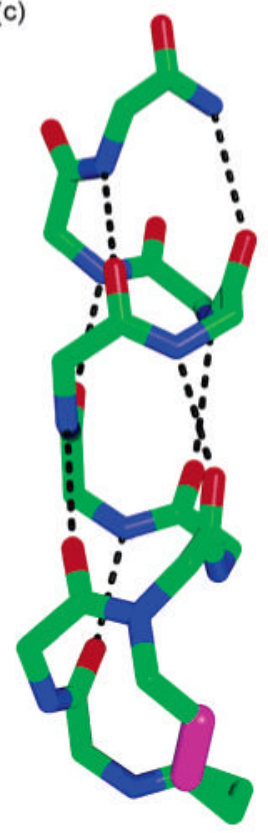

Figure 6.

NMR-derived structures of HBS $\alpha$-helix -3. ( $a$ and b) Side and top views of 20 lowest energy structures, and (c) lowest energy structure showing hydrogen-bonding pattern within the artificial $\alpha$-helix. -All carbon, nitrogen, and oxygen atoms are shown in green, blue, and red, respectively, with the exception of the trans alkene group which is shown in magenta. 


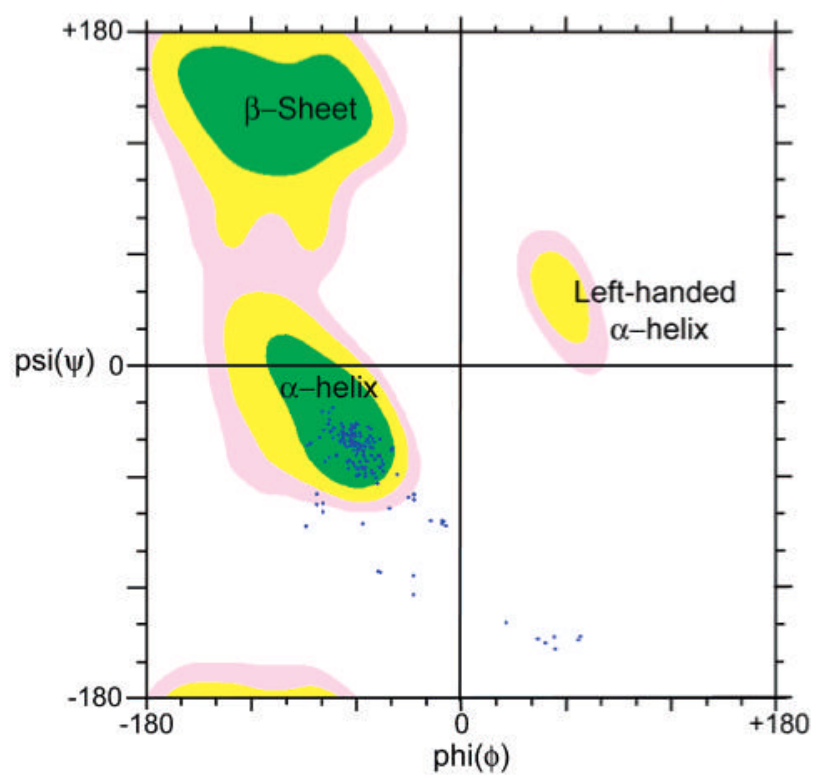

Figure 7.

Ramachandran plot representing the 20 lowest energy NMR structures. A vast majority of the values fall within the ideal $\alpha$-helix region with the exception of the $\varphi$ and $\psi$ values for the Q1 residue. This map was generated within the MolMol molecular graphics program. 39 


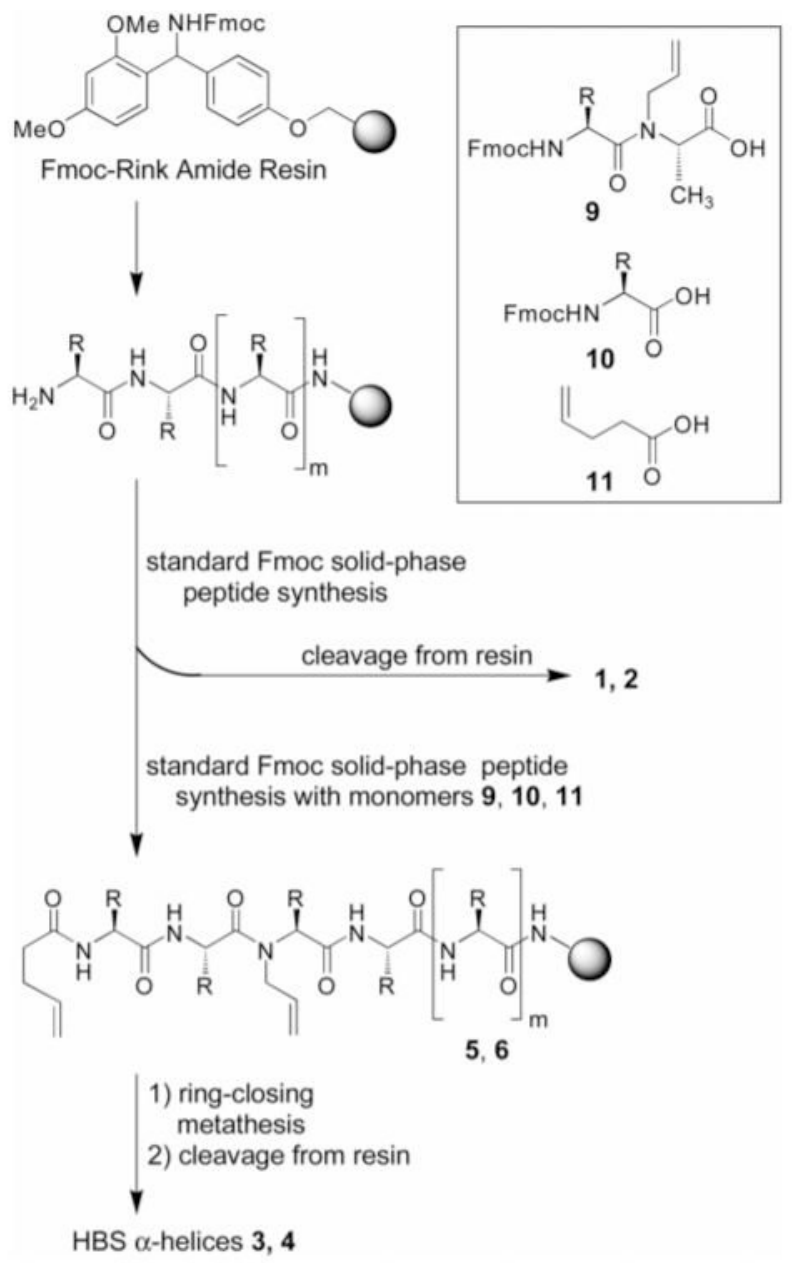

Scheme 1.

Solid Phase Synthesis of Peptides $\mathbf{1}$ and $\mathbf{2}$ and HBS $\alpha$-Helices $\mathbf{3}$ and $\mathbf{4}$ 
Table 1

Molar Ellipticities ( $[\theta] \mathrm{deg} \mathrm{cm} \mathrm{dmol}^{-1}$ ) at $\lambda=222,208$, and $191 \mathrm{~nm}$, Ratios of Ellipticities at 222 and $208 \mathrm{~nm}$, and Percent Helicity for Unconstrained Peptides and HBS $\alpha$-Helices

\begin{tabular}{|c|c|c|c|c|c|c|}
\hline peptides & solvent & {$[\theta]_{222}$} & {$[\theta]_{208}$} & {$[\theta]_{191}$} & {$[\theta]_{222} /[\theta]_{208}$} & $\%$ helicitye $e^{e}$ \\
\hline \multirow[t]{4}{*}{1} & PBS & -3223 & $-7937^{b}$ & $d$ & 0.41 & 14 \\
\hline & $20 \% \mathrm{ACN} / \mathrm{PBS}$ & -4893 & $-9055^{a}$ & $d$ & 0.54 & 21 \\
\hline & $10 \%$ TFE/PBS & -4670 & $-7234^{a}$ & $d$ & 0.65 & 20 \\
\hline & $20 \% \mathrm{TFE} / \mathrm{PBS}$ & -6047 & $-12008^{a}$ & $1452^{c}$ & 0.50 & 26 \\
\hline \multirow[t]{4}{*}{3} & PBS & -10816 & -9265 & $8505^{c}$ & 1.17 & 46 \\
\hline & $20 \% \mathrm{ACN} / \mathrm{PBS}$ & -14960 & -10424 & 22167 & 1.44 & 63 \\
\hline & $10 \%$ TFE/PBS & -15983 & -11380 & 24703 & 1.40 & 68 \\
\hline & $20 \%$ TFE/PBS & -19942 & -16382 & 38688 & 1.22 & 85 \\
\hline \multirow[t]{4}{*}{2} & PBS & -1423 & $-18370^{b}$ & $d$ & 0.08 & 6 \\
\hline & $20 \%$ ACN/PBS & -3488 & $-12042^{b}$ & $d$ & 0.29 & 15 \\
\hline & $10 \%$ TFE/PBS & -3117 & $-12656^{b}$ & $d$ & 0.25 & 13 \\
\hline & $20 \%$ TFE/PBS & -6787 & $-11502^{b}$ & 9169 & 0.59 & 29 \\
\hline \multirow[t]{4}{*}{4} & PBS & -7585 & $-9265^{a}$ & $1622^{c}$ & 0.82 & 32 \\
\hline & $20 \% \mathrm{ACN} / \mathrm{PBS}$ & -10682 & -8621 & 10023 & 1.24 & 45 \\
\hline & $10 \%$ TFE/PBS & -11200 & -8704 & 10370 & 1.29 & 47 \\
\hline & $20 \%$ TFE/PBS & -14543 & -11474 & 25400 & 1.27 & 62 \\
\hline \multicolumn{7}{|c|}{${ }^{a}$ Absorption band observed at $203 \mathrm{~nm}$. } \\
\hline \multicolumn{7}{|c|}{$b$ Absorption band observed at $198 \mathrm{~nm}$. } \\
\hline \multicolumn{7}{|c|}{${ }^{c}$ Absorption band observed at $189 \mathrm{~nm}$. } \\
\hline \multicolumn{7}{|c|}{${ }^{d}$ No positive absorption band observed. } \\
\hline
\end{tabular}


Summary of NMR Data for HBS $\alpha$-Helix 3

Table 2

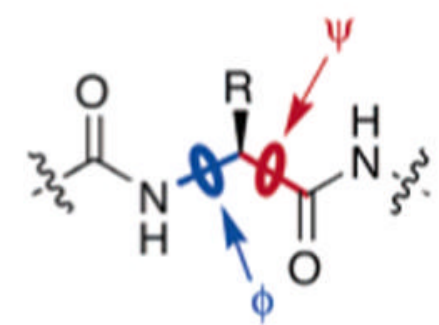

\begin{tabular}{|c|c|c|c|c|c|c|c|c|c|}
\hline residues: & $\mathbf{Q}^{1}$ & $\mathbf{V}^{2}$ & $\mathbf{R}^{4}$ & $Q^{5}$ & $L^{6}$ & $\mathbf{A}^{7}$ & $\mathbf{E}^{8}$ & $\mathbf{I}^{9}$ & $\mathbf{Y}^{10}$ \\
\hline${ }^{3} J_{\mathrm{NH}-\mathrm{C} \alpha \mathrm{H}}(\mathrm{Hz})$ & 8.4 & 4.0 & 4.4 & 4.8 & 4.4 & 3.3 & 4.8 & 6.0 & 6.9 \\
\hline$\underset{a}{\text { calculated } \varphi(\mathrm{deg})}$ & -95 & -58 & -62 & -65 & -62 & -52 & -65 & -74 & -81 \\
\hline $\begin{array}{l}\text { temperature } \\
\text { coefficient (ppb/ } \\
\Delta K)\end{array}$ & -4.45 & -8.88 & 2.70 & -2.64 & -5.69 & -4.50 & -2.98 & -3.26 & -5.85 \\
\hline $\begin{array}{l}\text { H/D rate constant } \\
\times 10^{-5}\left(\mathrm{~s}^{-1}\right)\end{array}$ & 8.0 & 11.1 & 0.6 & 2.2 & 1.6 & 3.7 & 16.6 & 3.2 & 11.0 \\
\hline $\begin{array}{l}\text { protection factor } \\
\left(\log k_{\mathrm{ch}} / k_{\mathrm{ex}}\right)^{\mathrm{b}, \mathrm{c}}\end{array}$ & 1.64 & 1.13 & 2.94 & 2.62 & 2.09 & 1.90 & 1.60 & 1.94 & 1.13 \\
\hline $\begin{array}{l}\text { stabilization, - } \\
\Delta \mathrm{G}(\mathrm{kcal} / \mathrm{mol})^{b}\end{array}$ & 2.18 & 1.47 & 3.94 & 3.51 & 2.80 & 2.54 & 2.12 & 2.33 & 1.48 \\
\hline
\end{tabular}

${ }^{a}$ Calculated according to the Karplus equation. ${ }^{28,35}$

${ }^{b}$ Calculated using the spreadsheet at http://hx2.med.upenn.edu/download.html.

$c_{k_{\mathrm{ex}}}$ : measured exchange rates. $k_{\mathrm{ch}}$ : intrinsic chemical exchange rate. 
Table 3

Summary of NMR Data for HBS $\alpha$-Helix 4

\begin{tabular}{|c|c|c|c|c|c|c|c|c|c|}
\hline residues: & $\mathbf{R}^{1}$ & $\mathbf{I}^{2}$ & $\mathbf{R}^{4}$ & $\mathbf{L}^{5}$ & $E^{6}$ & $\mathbf{E}^{7}$ & $\mathbf{K}^{8}$ & $\mathbf{Y}^{9}$ & $\mathbf{K}^{10}$ \\
\hline${ }^{3} J_{\mathrm{NH}-\mathrm{C} \alpha \mathrm{H}}(\mathrm{Hz})$ & 4.0 & 4.3 & 5.5 & 5.0 & 4.6 & 8.4 & 7.8 & 3.8 & 4.8 \\
\hline calculated $\varphi(\mathrm{deg})^{a}$ & -58 & -61 & -70 & -66 & -63 & -95 & -89 & -56 & -65 \\
\hline $\begin{array}{l}\text { temperature } \\
\text { coefficient }(\mathrm{ppb} / \Delta K)\end{array}$ & -4.58 & -9.53 & 1.50 & -4.17 & -4.81 & -3.64 & -4.77 & -5.18 & -3.53 \\
\hline $\begin{array}{l}\mathrm{H} / \mathrm{D} \text { rate constant } \mathrm{x} \\
10^{-4}\left(\mathrm{~s}^{-1}\right)\end{array}$ & 20.1 & 3.5 & 2.8 & 1.6 & 3.1 & 17.3 & 24.9 & 11.0 & 16.1 \\
\hline $\begin{array}{l}\text { protection factor } \\
\left(\log \mathrm{k}_{\mathrm{ch}} / \mathrm{k}_{\mathrm{ex}}\right)^{\mathrm{b}, \mathrm{c}}\end{array}$ & 0.25 & 0.62 & 1.31 & 1.11 & 1.11 & 0.88 & 0.54 & 0.48 & 0.48 \\
\hline $\begin{array}{l}\text { stabilization, }-\Delta G \\
(\mathrm{kcal} / \mathrm{mol})\end{array}$ & -0.14 & 0.67 & 1.72 & 1.44 & 1.43 & 1.10 & 0.53 & 0.41 & 0.41 \\
\hline
\end{tabular}

${ }^{a}$ Calculated according to the Karplus equation. ${ }^{28,} 35$

${ }^{b}$ Calculated using the spreadsheet at http://hx2.med.upenn.edu/download.html.

$c_{k_{\text {ex }}}$ : measured exchange rates. $k_{\mathrm{ch}}$ : intrinsic chemical exchange rate. 